\title{
Fabrication of Aluminium Metal Matrix Composite by Friction Stir Processing - A Review
}

\author{
${ }^{1}$ Himanshu Singh, ${ }^{2}$ Sandeep Srivastava, ${ }^{3}$ Suraj Kumar Yadav, ${ }^{4}$ Robin Kumar Shekhar, ${ }^{5}$ Mr Kapil Dev \\ Mechanical Engineering Department, JSS Academy of Technical Education, \\ Noida, Uttar Pradesh, India
}

\begin{abstract}
Friction Stir Processing (FSP) is a new approach for successful fabrication of Aluminium Metal Matrix Composites (AMCs) with required properties of Nitinol (NiTi) Shape Memory Alloys (SMA). This reinforcement agent is used for heightening the mechanical properties of aluminium alloy with Shape Memory Effect but such fabrication was not possible without defects such as critical intermetallic formation between reinforced particles and matrix. So we present a creative strategy to fabricate Al7075-T6/NiTi composites by FSP. It has been found that the groove filling method results in a more homogenous distribution compared to the multi-holes filling method. In this innovative strategy, we are going to use the groove filling method with a new FSP tool design for the linear distribution of reinforcement particles in grooves. This FSP tool will be used with the help of a Vertical Milling Machine.
\end{abstract}

Keywords: Metal Matrix Composites, Friction Stir Processing, Shape Memory Alloys, Microstructure Defects, Homogeneous Distribution

Introduction

Embedding particulate reinforcements in aluminium matrices to form Aluminium Matrix Composites (AMCs) is an attractive, alternative, and innovative process to enhance the mechanical properties of aluminium alloys. In the previous studies of Heinz et al. (2000) and Williams and Starke (2003), the authors have shown that high-strength aluminium alloys, especially Al7075, are widely used in the aerospace industry due to their high strength-to-density ratio. [1]

Prakrathi Sampath, Vineeth Krishna Parangodath, Kota Rajendra Udupa, Udaya Bhat Kuruveri (2015) Friction Stir Processing is a novel solid-state mechanical technique in synthesizing MMNCs with a focus on surface and subsurface region and was developed with the concepts of friction Stir Welding. The surface properties of a material can be modified without changing the bulk properties of the base metal. FSP can alter surface properties according to the requirements. The working tool has 2 main parts- a rotating tool with a pin and shoulder. Rotating tool with a pin inserts into the material surface and moves. Functions of a rotating tool are (1) heating the specimen in the localized zone (2) moving and transporting the materials within the processing zone and (3) facilitating mixing up of base material and externally added material to produce a composite material within the processed zone. After completion of the process, a metal matrix composite with higher wear resistance and hardness is formed. [2]

Sharma et. al (2015) introduced reinforcement particles into the aluminium matrix to develop superior mechanical properties, such as tensile strength. [3]

Ramesh and Murugan the experimented with AA 7075-T651 plates. The thickness of the plate is $6.35 \mathrm{~mm}$ with a depth of the groove is $2.5 \mathrm{~mm}, 0.5 \mathrm{~mm}$ width, and $100 \mathrm{~mm}$ length along with the plate. The reinforcement particle used is Boron carbide powder with the diametric size of 5 micrometers and that is used to fill the grooves. They used one pass and multi passes up to 3 and found the maximum hardness of $64 \mathrm{BHN}$ at rotation speed $575 \mathrm{rpm}$ and travel speed $60 \mathrm{~mm} / \mathrm{min}$ with 2 passes. A rise of $62 \%$ was found in the average hardness of the processed surface than that of the base metal AA 7075-T651. [4]

Sudhakar et. al after studying the processing of base material A17075-O alloy with reinforcement material of Boron Carbide of the diametric size of $30 \mu \mathrm{m}$, at $960 \mathrm{rpm}$ rotating speed and $60 \mathrm{~mm} / \mathrm{min}$ traveling speed maximum hardness and tensile strength were achieved. [5]

Yongxian et. al done fabrication of AZ31 Mg matrix composite using reinforcements material such as carbon nanotubes of SiC. The process used is Direct Friction Stir Processing (DFSP) to generate a composite surface. In this method of DFSP, there is no such need for grooves to insert ceramic powder. DFSP method has increased the microhardness of the surface from $57.77 \mathrm{HV}$ to $115.51 \mathrm{HV}$ using a hollow tool and without a pin to modify the composite surface. DFSP is used on the AZ31 plate and found the thickness of the composite layer of $150 \mu \mathrm{m}$.

In the recent study, a new tool design is proposed. FSP tool with a pin is used to add SiC particles directly to the stirring zone through holes in the shoulder face. The FSP tool pin has proved to be advantageous in improving the mixing process of ceramic particles with base metal and increased the heat generated by friction. Different size particles are used to study the effects of particle size on the hardness of AA7075-T651 alloy. During the process, mechanical pressure is applied using a helical spring so that ceramic particles fall into the groove. [6] 


\section{Experimental Procedure}

Aluminium AA7075-T6 plates of size 200 x 50 x $6.35 \mathrm{~mm}$ were used. The chemical composition of AA7075-T6 is given in Table 1. The tool is made of high chromium alloy steel, The FSP process parameters are identified as rotational speed (RS), traveling speed (TS), and particle size of NiTi and Al7075-T6 (PS).

The addition of NiTi particles and A17075-T6 particles into the matrix alloy significantly increases the hardness and decreases elongation of the composites in comparison with those of the base alloy [7]. NiTi with two different particle sizes 19 and $3.5 \mu$ m. NiTi and Al7075 powders $19 \mu \mathrm{m}$ and $3.5 \mu \mathrm{m}$ have specifications shown in Table 2. Particles sizes are selected according to previous references [8].

A vertical milling machine was used to prepare the FSP plates, see Figure 2. The experimental parameters were selected as shown in Table 3. The specimens were prepared from the FSP samples.

The Tool design is shown in Figure 3. The hollow tool is used to fill it with NiTi and Al7075-T6 particles. The thickness of metal for the shoulder face is $5 \mathrm{~mm}$. The generated heat equation below shows the thickness of the shoulder isn't an effective factor for shoulder thickness on the amount of generated heat.

$\mathrm{q}=\delta \mathbf{E} \mu \mathrm{PN}(\mathrm{r} \omega-\mathrm{v} \mathbf{x} \sin \theta)$

Where:

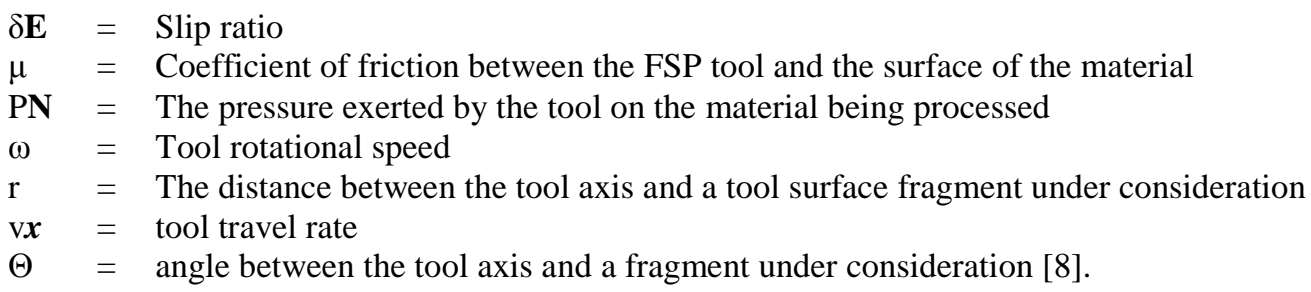

A thin disc of polystyrene foam has a thickness of $2 \mathrm{~mm}$; it is placed inside the tool cavity to prevent the fall of the Al7075T6 and NiTi powder at the beginning of the process. At the beginning of the FSP process, the heat of the tool rises gradually to reach a high temperature near 80 percent of the melting temperature of the base metal (about $381.6{ }^{\circ} \mathrm{C}$ ) [9]. At $240{ }^{\circ} \mathrm{C}$ temperature, the polystyrene disc will melt and evaporate [10], which allows the powder particles to pass through holes. After the disk evaporating, powder particles will extrude through holes due to the pressing of the piston due to releasing of compressed spring. A piston of steel is put in the cavity after filling the tool with 2 grams of NiTi and Al7075-T6 powder. It has been used to push the powder. A helical spring is used to supply a continuous force to press the Mixed Powder to extrude through the two holes, see Figure 3. A piece of aluminium foil is placed on the shoulder to close two holes before starting the process After starting the foil will tear by friction between the shoulder and workpiece surface and polystyrene will melt and evaporate due to the increased temperature of the tool when the tool shoulder starts to touch the workpiece.

The experiments were designed based on two level-three factors factorial technique. The developed and design matrix is shown in Table 4. Four samples were prepared as shown in Table 5. Four specimens were prepared for surface inspection. After mounting and preparing the specimens, they are inspected by Vickers hardness test. Microhardness is measured on the upper surface and thickness side of the processed surface.

Table 1: Chemical Composition of Al 7075-T6 Alloys

\begin{tabular}{|c|c|c|c|c|c|c|c|c|}
\hline Element & $\mathbf{Z n}$ & $\mathbf{M g}$ & $\mathbf{C u}$ & $\mathbf{F e}$ & $\mathbf{S i}$ & $\mathbf{M n}$ & $\mathbf{C r}$ & Al \\
\hline $\mathrm{Wt} \%$ & 5.85 & 2.51 & 1.65 & 0.1 & 0.040 & 0.03 & 0.2 & Bal \\
\hline
\end{tabular}

Table 2: NiTi and Al7075-T6 Powder Specifications

\begin{tabular}{|l|l|}
\hline Median grain size $(\boldsymbol{\mu m})$ of Al7075T6 & (a) $3.5+-0.5$ or (b) $19+-0.5$ \\
\hline Median grain size $(\boldsymbol{\mu m})$ of Nitinol & (b) $3.5+-0.5$ or (b) $19+-0.5$ \\
\hline Purity & $97+-97.8$ \\
\hline
\end{tabular}

Table 3: Selected Parameter for FSP

\begin{tabular}{|c|c|c|}
\hline $\begin{array}{c}\text { Rotating Speed } \\
(\mathbf{r p m})\end{array}$ & $\begin{array}{c}\text { Traveling Speed } \\
(\mathbf{m m} / \mathbf{m i n})\end{array}$ & $\begin{array}{c}\text { Particle Size } \\
(\boldsymbol{\mu m})\end{array}$ \\
\hline 930 & 40 & 19 \\
\hline 1460 & 60 & 3.5 \\
\hline
\end{tabular}




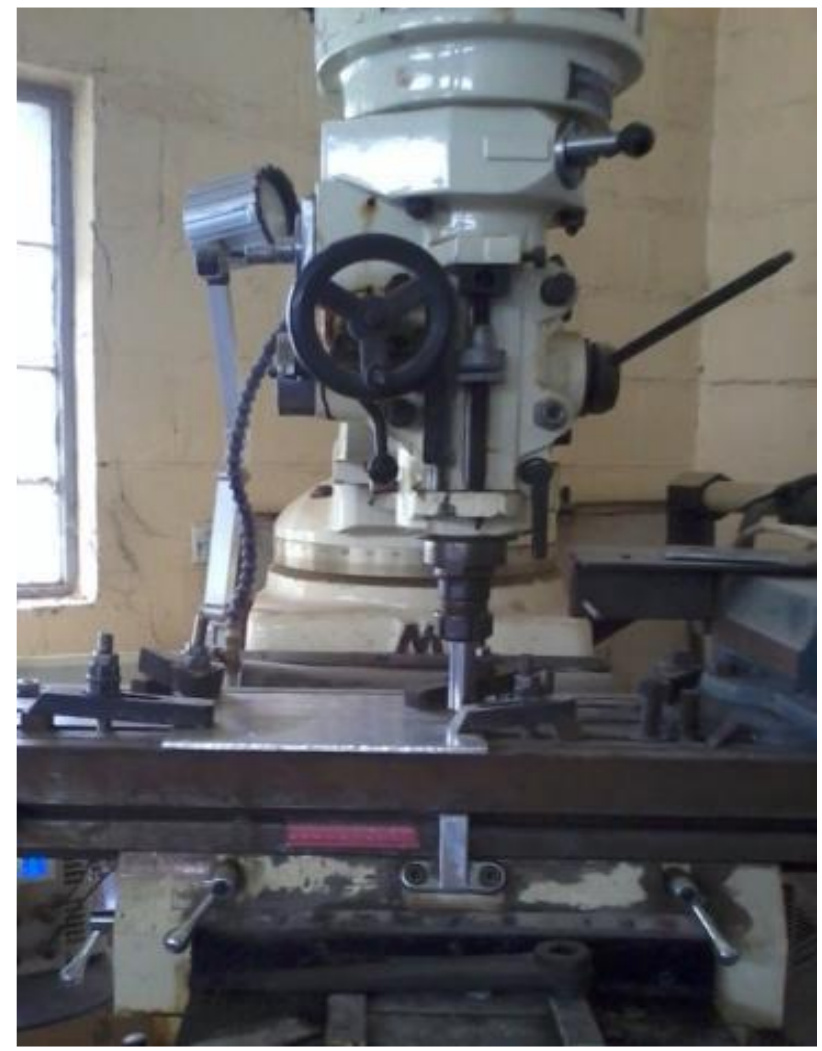

Figure 1: Vertical Milling Machine Used for FSP
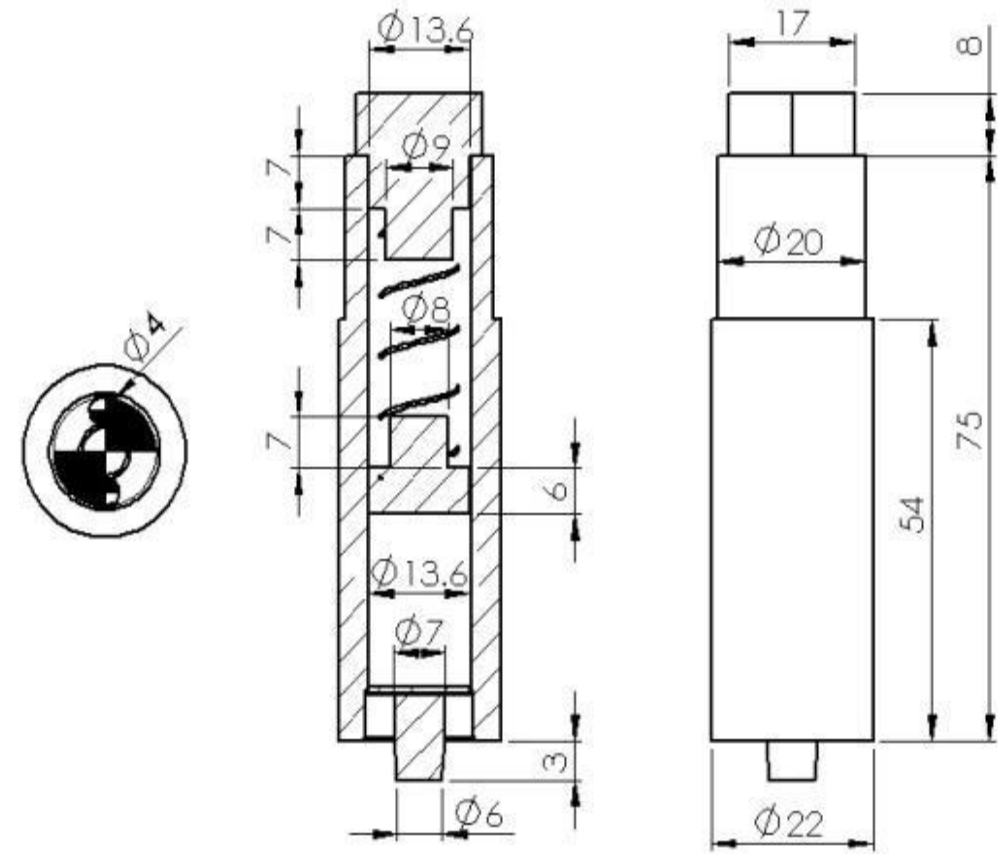

Figure 2: Sketch of Tool Design and its Dimensions 


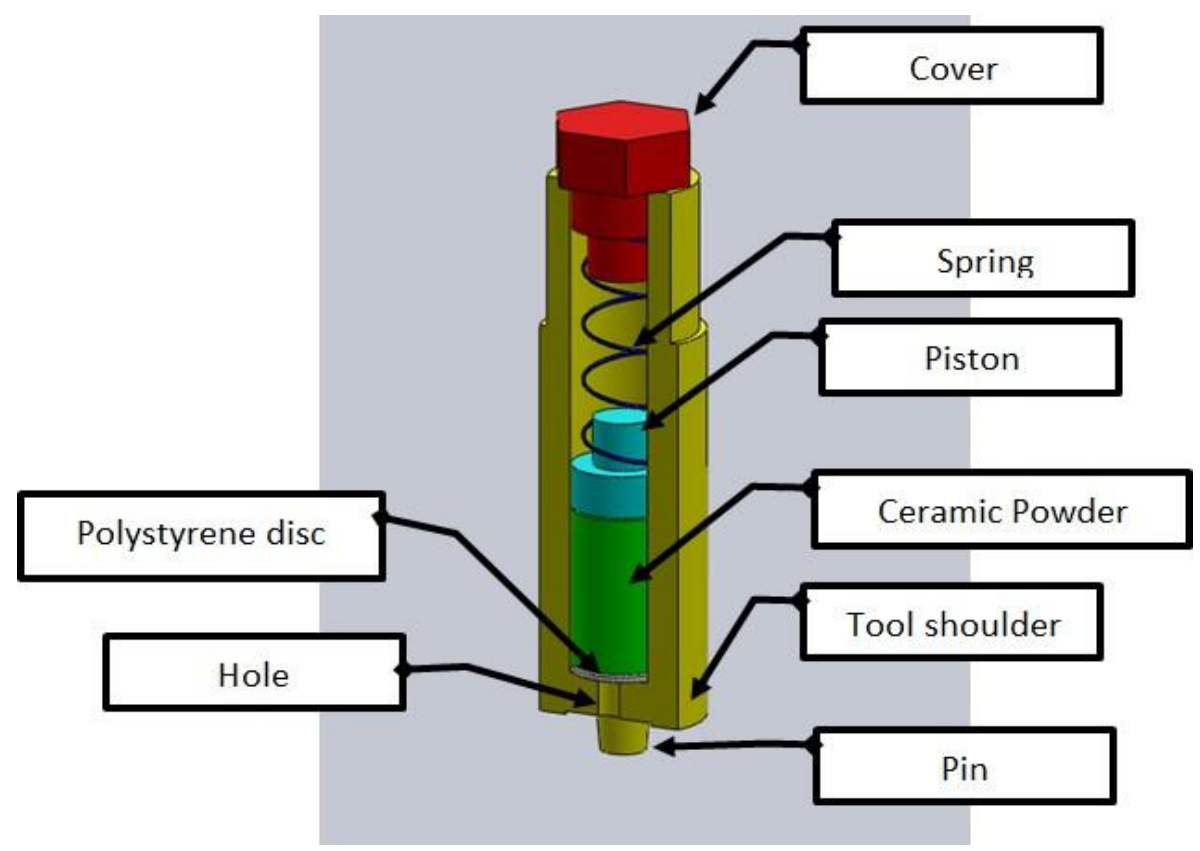

Figure 3: Section View for Tool Assembly

Table 4: Design Matrix and Estimated Values

\begin{tabular}{|c|c|c|c|}
\hline \multirow{2}{*}{ Experimental Trial } & \multicolumn{3}{|c|}{ Design Matrix } \\
\cline { 2 - 4 } & RS $(\mathrm{rpm})$ & TS $(\mathrm{mm} / \mathrm{min})$ & PS $(\mu \mathrm{m})$ \\
\hline 1 & 930 & 60 & 19 \\
\hline 2 & 930 & 40 & 3.5 \\
\hline 3 & 1460 & 60 & 3.5 \\
\hline 4 & 1460 & 40 & 19 \\
\hline
\end{tabular}

\section{Results and Discussion}

Microhardness is measured for the four surfaces. In table 5 microhardness for 4 specimens is presented. In figure 4 the hardness measurements are presented. The highest microhardness is of specimen S3 shown in Figure 5. Al7075-T6 softens and its hardness drops in the processed zone refer to Figure 6. After adding the NiTi and Al7075-T6 particles to the alloy surface, the hardness increases due to the insertion of the hard particles in the alloy. The increase in hardness was attributed to the presence of powders that have a high modulus of rigidity and for fine dispersion of NiTi and Al7075-T6 particles and fine grain size of the Aluminium matrix [12]. Pressing the NiTi and Al7075-T6 powder in the stirring zone improves the distribution and insertion in the base metal. The effects of traveling speed, rotating speed and SiC particles size on hardness were presented in Figure 7. By using the mathematical equations, graphs have been plotted between traveling speed vs Vickers hardness, Rotating speed vs Vickers hardness and particle size of particles vs Vickers hardness. From Figure 7 it has been observed that when the traveling speed increases hardness due to the reduction in heat input increases. when traveling speed is low the amount of heat input is high due to stirring and friction effects which will be in the same area for a long time. When traveling speed increase the heat input for the same area (as mentioned before) will be for a lesser time, therefore the growth of base metal grains will be less.

Table 5: Average Hardness of Specimen's Measurements

\begin{tabular}{|c|c|c|c|c|}
\hline \multirow{2}{*}{ Specimens No. } & \multicolumn{3}{|c|}{ Parameters } & \multirow{2}{*}{ HV } \\
\cline { 2 - 4 } & RS (rpm) & TS $(\mathbf{m m} / \mathbf{m i n})$ & PS $(\boldsymbol{\mu m})$ & \\
\hline S1 & 930 & 60 & 19 & $?$ \\
\hline S2 & 930 & 40 & 3.5 & $?$ \\
\hline S3 & 1460 & 60 & 3.5 & $?$ \\
\hline S4 & 1460 & 40 & 19 & $?$ \\
\hline
\end{tabular}




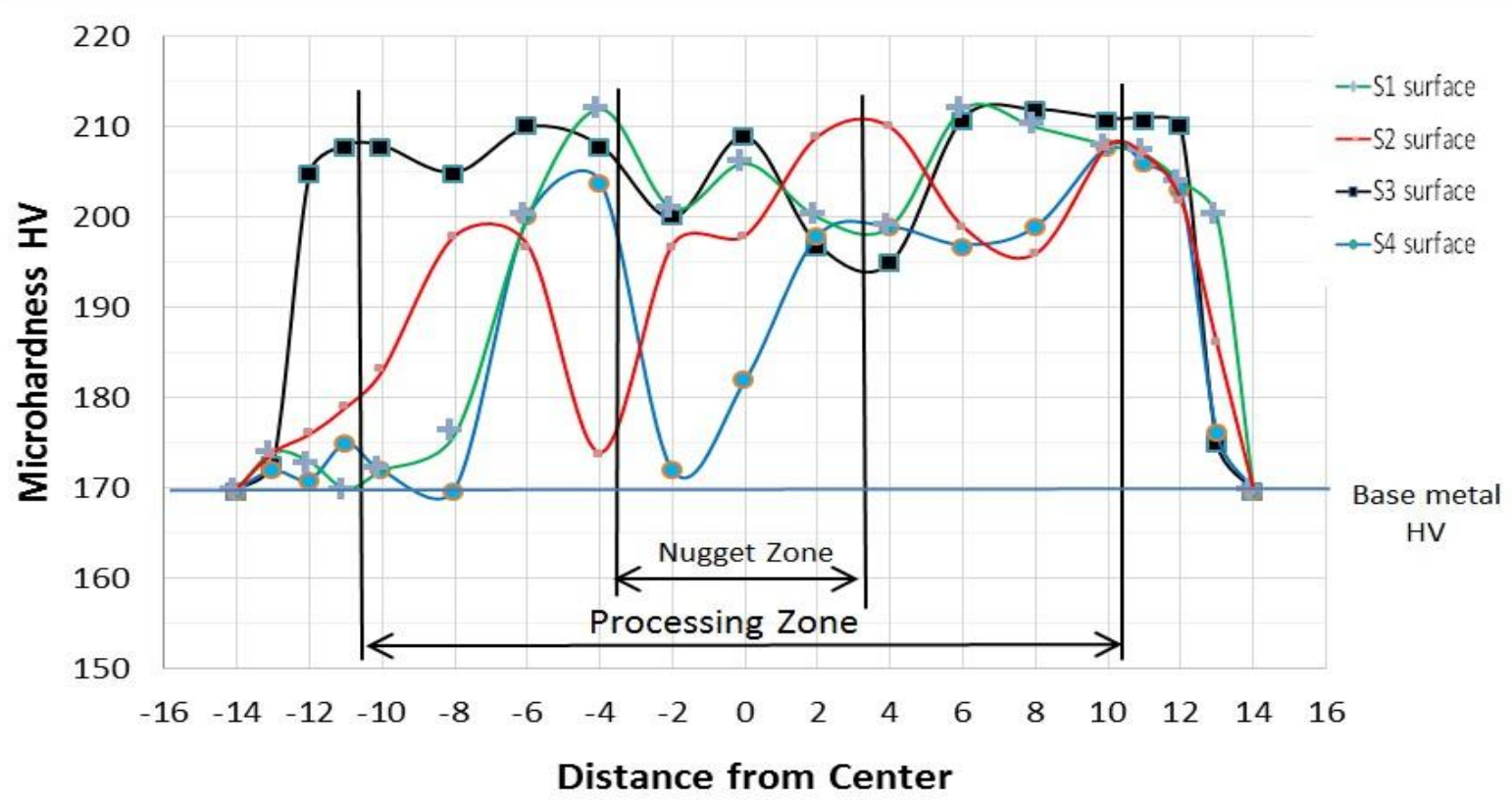

Figure 4: Hardness Measurement for Processing Surface

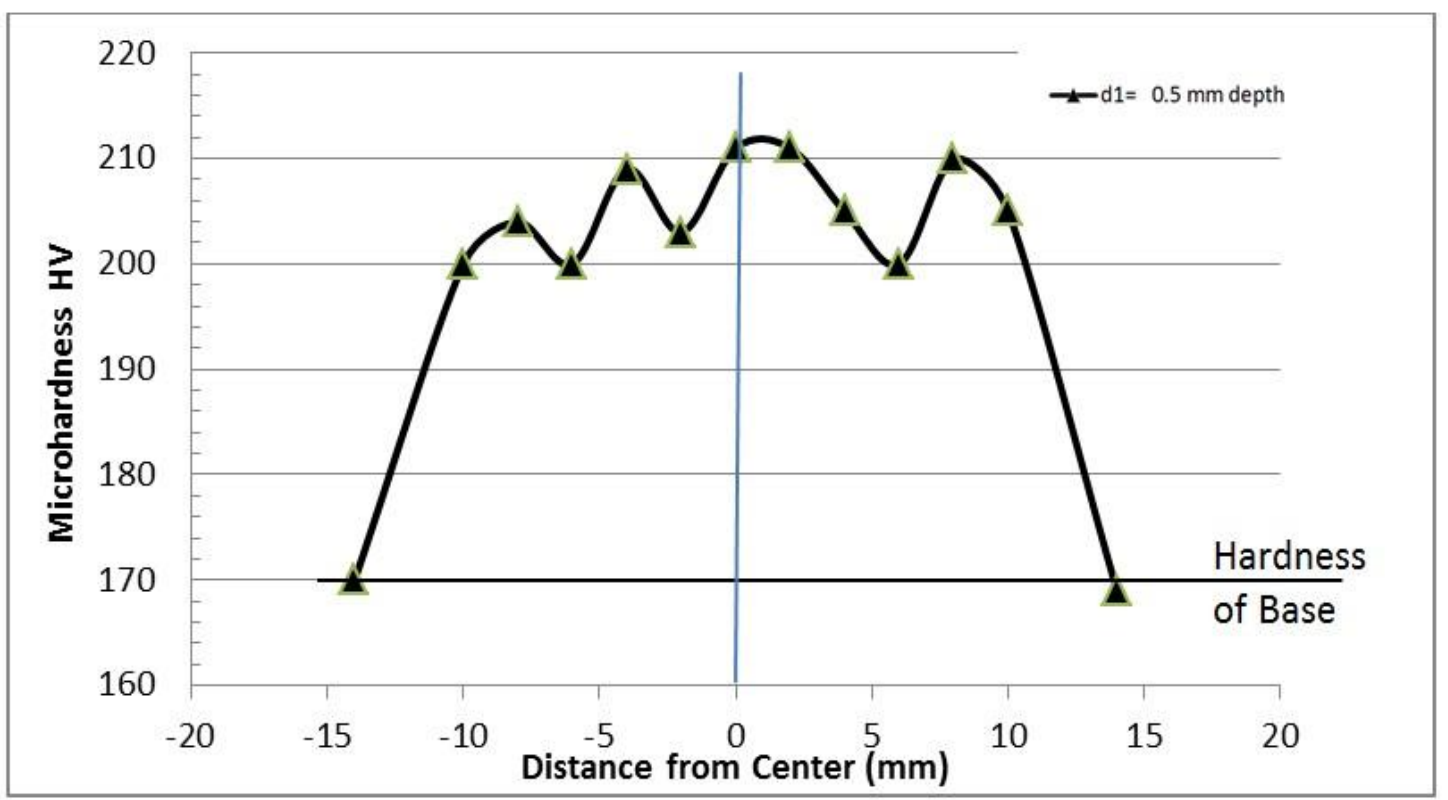

Figure 5: Hardness Measurement for Specimen S3 


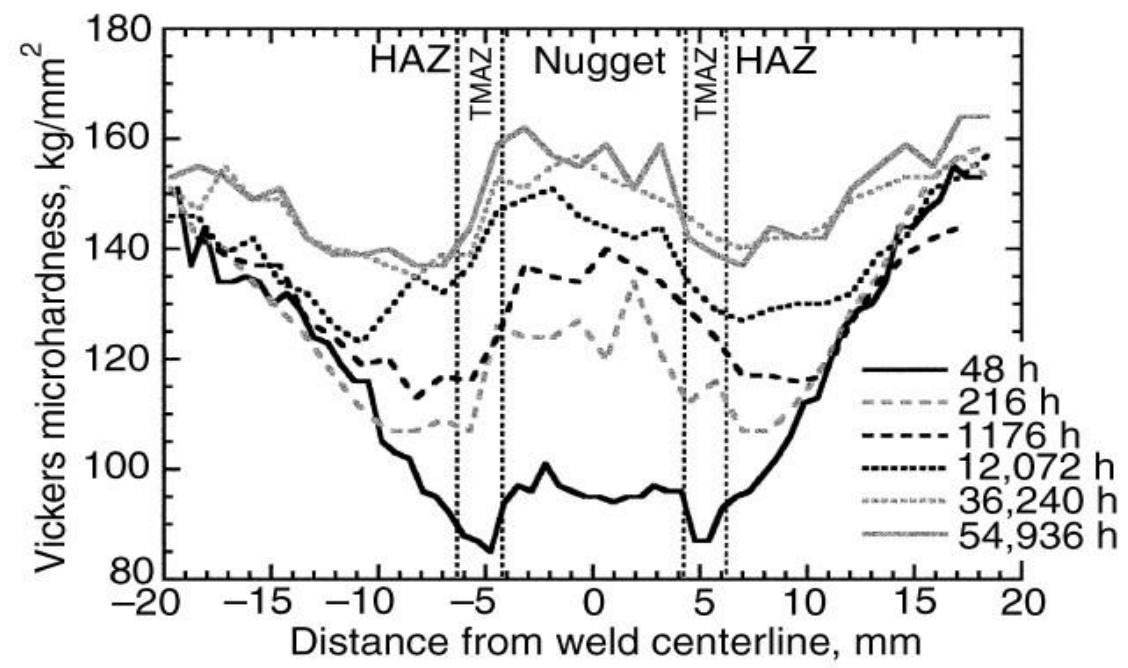

Figure 6: Effect of FSP on the Hardness of Welded Joint of Al 7075-T651 after Different Hours (h) for Natural Aging [13]

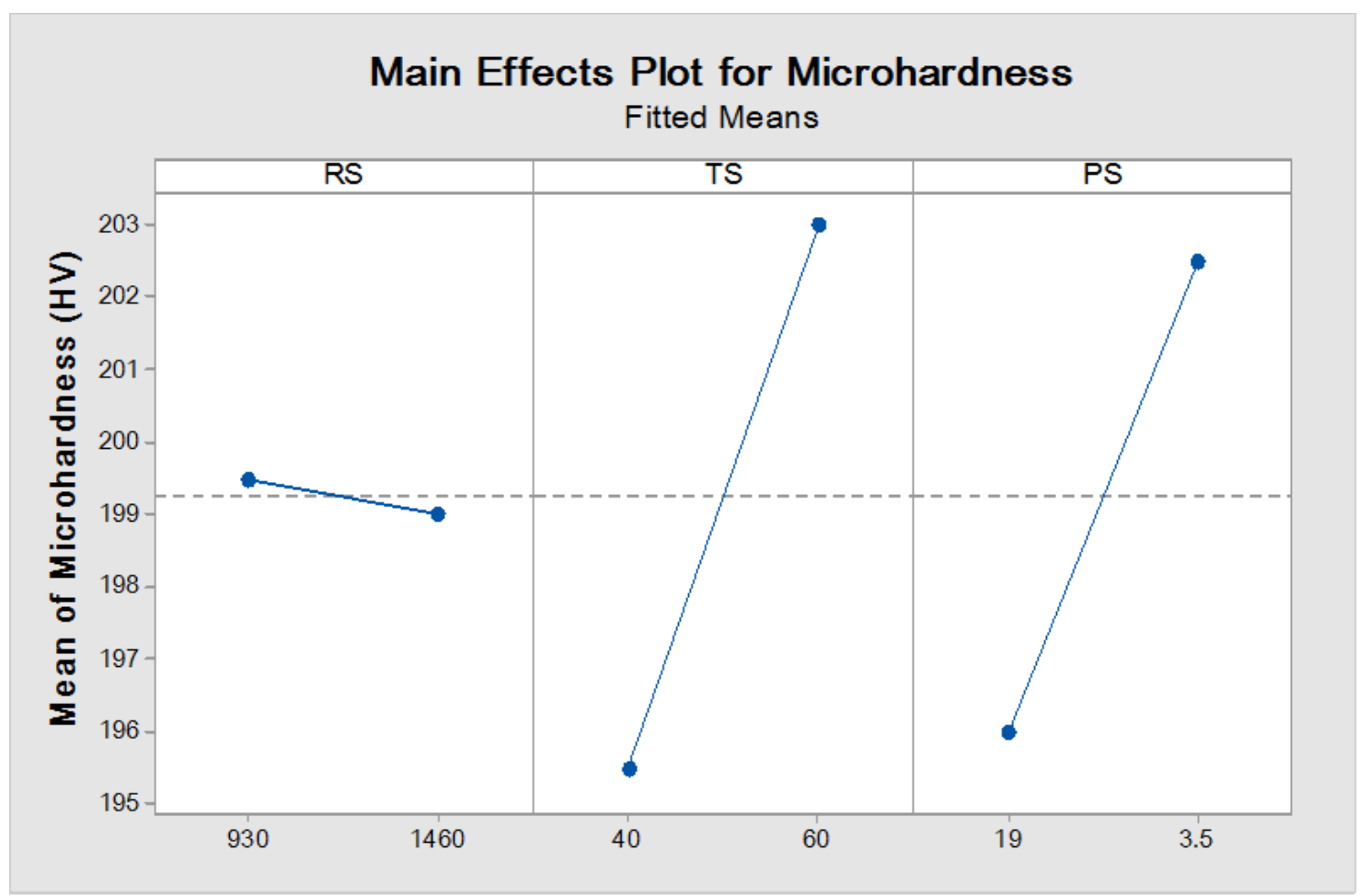

Figure 7: Effect of Parameters of

Rotating Speed (RS), Traveling Speed (TS), and Particle Size (PS) on Hardness

\section{Conclusions}

From the recent study, it can be concluded that:

1. The microhardness value will be highest when the processing speed is $1,460 \mathrm{rpm}$ and traveling speed is $60 \mathrm{~mm} / \mathrm{min}$ respectively.

2. FSP using particle size $3.5 \mu \mathrm{m}$ of NiTi and A17075-T6 particles will show better microhardness results.

3. Surface hardness will increase drastically by using a new tool designed for FSP. Mechanical pressing of the powder succeeds in inserting the NiTi and A17075-T6 particles into the processing zone.

\section{References}

[1] Heinz A., Haszler A., Keidel C., Moldenhauer S., Benedictus R., Miller W. S., 2000, Recent development in aluminum alloys for aerospace applications, Mater. Sci. Eng., 280, 102-107

[2] Prakrathi Sampath, Vineeth Krishna Parangodath, Kota Rajendra Udupa, Udaya Bhat Kuruveri, 2015, Fabrication of Friction Stir Processed Al-Ni Particulate Composite and Its Impression Creep Behaviour. Journal of Composites, Volume 2015, Article Id 428630 
[3] Sharma V., Prakash U., Kumar B. V. M., 2015, Surface composites by friction stir processing: a review, J. Mater. Process. Technol. 224, 117-134

[4] R. Ramesh, N. Murugan, 2013, Microstructure and Metallurgical Properties of Aluminium 7075-T651 Alloy / B4c 4\% Vol. Surface Composite by Friction Stir Processing, Advanced Materials Manufacturing \& Characterization, Vol 3, Issue 1, 301306

[5] Sudhakar I, Madhusudhan Reddy G, Srinivasa Rao K, 2013, Efficacy of Friction Stir Processing in Fabrication of Boron Carbide Reinforced 7075 Aluminium Alloy. International Conference on Multidisciplinary Research \& Practice, Vol I, pp. 162-165

[6] Yongxian Huang, Tianhao Wang, Weiqiang Guo, Long Wan, Shixiong Lv, 2014, Microstructure and surface mechanical property of AZ31 Mg/SiCp surface composite fabricated by Direct Friction Stir Processing. Materials and Design, Vol 59, pp. 274-278

[7] A. R. I. Kheder, G. S. Marahleh, D. M. K. Al-Jamea, 2011, Strengthening of Aluminum by SiC, Al2O3 and MgO. Jordan Journal of Mechanical and Industrial Engineering, Vol. 5, 533-541

[8] Zhangwei Wang, Min Song, Chao Sun, Yuehui He, 2011, Effects of particle size and distribution on the mechanical properties of SiC reinforced Al-Cu alloy composites, Materials Science and Engineering, Volume 528, Issue 3, 1131-1137

[9] T. Azimzadegan, Gh. Khalaj, M. M. Kaykha, A. R. Heidari, 2011, Ageing Behavior of Friction Stir Welding AA7075-T6 Aluminum Alloy. Computational Engineering in Systems Applications, Volume II, 183-187

[10] James E. Mark., 2007, Polymer data handbook. Oxford University Press Inc. 832, 1999

[11] Omar Hatamleh, Jed Lyons, Royce Forman, 2007, Laser and shot peening effects on fatigue crack growth in friction stir welded 7075-T7351 Al alloy joints. International Journal of Fatigue 29, 421-434

[12] Nelson Netto, Lv Zhao, Jeroen Soete, Grzegorz Pyka, Aude Simar, 2020, Manufacturing high strength aluminum matrix composites by friction stir processing, Journal of Materials Processing Technology, Volume 283

[13] C. D. Marini, Nanang Fatchurrohman, Zuhairah Zulkfli, 2020, Morphological study of friction stir processed aluminium metal matrix composites, Elsevier Ltd.

[14] Tiryakioglu M., Netto N., 2018, Friction Stir Processing: Effect on Microstructure and Mechanical Properties in Cast Aluminum Alloys

[15] Ranjit Bauri, Devinder Yadav, August 2017, Matrix composites by friction stir processing, DOI: 10.1016/C2016-0-04019-6

[16] Paul A. Rometsch, Yong Zhang, 2014, Steven Knight, Heat treatment of 7xxx series aluminium alloys - Some recent developments, Transactions of Nonferrous Metals Society of China, Volume 24, Issue 7

[17] P. A. Kumar, H. C. Madhu, A. Pariyar, C. S. Perugu, S. V. Kailas, U. Garg, P. Rohatgi, 2019, Friction stir processing of squeeze cast A356 with surface compacted graphene nanoplatelets (GNPs) for the synthesis of metal matrix composites, Materials Science \& Engineering, DOI: 10.1016/j.msea.2019.138517

[18] Chih-Wei Huang, Jong-Ning Aoh, Friction Stir Processing of Copper-Coated SiC Particulate-Reinforced Aluminum Matrix

[19] Mishra R. S., Ma Z. Y., Charit I., 2003, Friction stir processing: a novel technique for fabrication of surface composite, Mater. Sci. Eng. A 341, 307-310

[20] Netto N., Tiryakioğlu M., Eason P. D., 2018, On Si redistribution during friction stir processing of cast Al-7\% Si-0.4\% Mg alloys, Martin O. (Ed.), Light Metals 2018. Springer International Publishing, Cham, pp. 417-422

[21] Waheed S. AbuShanab, Essam B. Moustafa. Effects of friction stir processing parameters on the wear resistance and mechanical properties of fabricated metal matrix nanocomposites (MMNCs) surface

[22] Girija Moona, R S Walia, Vikas Rastogi, Rina Sharma, February 2018, Aluminium metal matrix composites: A retrospective investigation a CSIR-National Physical Laboratory, Indian Journal of Pure \& Applied Physics, Vol. 56, pp. 164-175

[23] Padmakumar A. Bajakke, Vinayak R. Malik, Anand S. Deshpande, Particulate metal matrix composites and their fabrication via friction stir processing, Materials And Manufacturing Processes, DOI: 10.1080/10426914.2019.1605181

[24] Isaac Dinaharan, Esther Titilayo Akinlabi, 2018, Low cost metal matrix composites based on aluminum, magnesium and copper reinforced with fly ash prepared using friction stir processing

[25] Karnezis P A, Durrant G, Cantor B, 1998, Characterization of reinforcement distribution in cast Al-alloy/SiC composited. Mater Charac, 97-109

[26] Rohatgi P. K., 2006, Applications of fly ash in synthesizing low cost Metal Matrix Composites for automotive and other engineering applications, JOM, Vol. 58, Issue No. 11, pp. 71-76, 2006

[27] T. W. Clyne, F. R. Jones, 2006, Metal matrix composites: matrices and processing, A. Mortensen (Ed.), Concise Encyclopedia of Composite Materials, $2^{\text {nd }}$ ed., Elsevier Publications 